\title{
Phytochemical Profiling and Bioactivities of Pholidota pallida Lindl
}

\author{
Seema Akter, Mohammed Kamrul Huda, Minhajur Rahman*, Mohammed Mozammel Hoque, \\ Tarina Akter Eva \\ Department of Botany, University of Chittagong, Chittagong-433, Bangladesh
}

*Corresponding Author: Minhajur Rahman, Department of Botany, University of Chittagong, Chittagong-433, Bangladesh

\begin{abstract}
In the present work, Pholidota pallida was explored for its phytochemicals along with its bioactivities. The qualitative screening of plant extract confirmed the presence of alkaloids, flavonoids, terpenoids, tannins, steroids and traces of quinone and coumarin in it. Four fractions viz. Methanol (FM), $n$ Hexane (FH), Butanol-1(BW) and Dichloromethane (FD) of methanolic crude of its leaf, stem and root were investigated for free radical scavenging, anti-inflammatory and anti-microbial activities. The responses were very unique for different dose and plant parts. The highest scavenging activity exhibited by the BW of bulb was $98.94 \%$ at $50 \mu \mathrm{g} / \mathrm{ml}$ dose. The highest anti-inflammatory activity was observed in FD of the plant leaf which was $79.16 \%$. The inhibitory effect of different parts of the plant against four pathogenic bacteria was varied i.e. for $S$. aureus (FD of root; $17.5 \mathrm{~mm}$ ), for B. subtilis (FD of bulb; $16.5 \mathrm{~mm}$ ), for S. typhii (BW of root; $12 \mathrm{~mm}$ ), for $B$. cereus ( $B W$ of root; $9.5 \mathrm{~mm}$ ) and root was found most effective part. The investigation indicates that, Pholidota pallida is a medicative plant having bountiful phytochemicals with antioxidant, antiinflammatory and antimicrobial actions.
\end{abstract}

Keywords: Phytochemicals, anti-microbial, anti-oxidant, anti-inflammatory.

\section{INTRODUCTION}

Orchidaceae family has huge therapeutic potential and such plants are utilized as therapeutics since ancient times ${ }^{[1]}$. Orchids have been also used in traditional system of medicine for various ailments ${ }^{[2]}$. The tubers and pseudobulbs of Orchis latifolia, Orchis mascula, Cymbidium aloifolium, Zeuxine strateumatica, and some species of Dendrobium, Eulophia and Habenaria are restorative and prescript for various diseases ${ }^{[3]}$. Vanda is a well-known anti-inflammatory plant ${ }^{[4-5]}$ and antiproliferative against various cancer types ${ }^{[6]}$. Contrariwise, biological studies also apprise that, orchids harbor phytochemicals physic for fatal diseases ${ }^{[7]}$. Thence, orchid derived compounds have been receiving tremendous attention as therapeutics ${ }^{[8]}$.

Bangladesh is also a reservoir of 178 orchid species of which 26 were reported to have ethnomedicinal uses ${ }^{[9]}$. Pholidota pallida is an indigenous epiphytic orchid of Bangladesh with the pseudobulbs occurring in the plains and as well as in elevation ${ }^{[10]}$. It is a traditional haemostate and healing of insomnia, fractured bones, nasal, abdominal and rheumatic pains ${ }^{[11-18]}$. But, none of above mentioned therapeutic properties of this orchid has yet been studied regarding its pharmacological value or active chemical constituents. A study on the pharmaceutical value of this medicinal orchid would be the step to explore a possible sustainable use of it. Considering all these factors, Pholidota pallida was picked for exploring its phytochemicals and bioactivities through standard methods.

\section{MATERiALS AND MeTHOdS}

Leaf, stem and root extracts of Pholidota pallida Lindl. were used in the present work. For extraction, naturally grown plant sample collected from Teknaf, Cox's bazar was cleaned, chopped, air dried at room temperature and finally ground into coarse powder. It was then ground into coarse powder by using grinding machine and stored in airtight container for further investigation. Mixing of one part with another was carefully avoided. Extract was filtered through Whatman No.1 filter paper and evaporated to dryness under vacuum below $50{ }^{\circ} \mathrm{C}$ to get the blackish extract. Then the concentrated crude extract was separated into four different solvent systems (Methanol, n-Hexane, Butanol-1, 
Dichloromethane) following the Kupchan method. Standard methods of Sofowara ${ }^{[19]}$, Trease and Evans ${ }^{[20]}$, Harbrone ${ }^{[21]}$ were followed for qualitative assessment of different secondary metabolites viz. Alkaloids, Phlobatannins, Flavonoids, Saponins, Tannins, Terpenoids, Steriods, Glycosides, Anthroquinone, Quinine and Coumarin. Antimicrobial activity of the plant extract was studied according to Bauer et al ${ }^{[22]}$, antioxidant activity was determined according to Brand-Williams et al. ${ }^{[23]}$, using DPPH and anti inflammatory activity on egg albumin was assessed according to Shinde $e t$ al. ${ }^{\text {[24] }}$. Each set of experiment was replicated thrice.

\section{RESULTS AND DISCUSSION}

The therapeutic properties of medicinal plants arise from the secondary metabolites present in them ${ }^{[25]}$. Hence, the secondary metabolites i.e alkaloids, Phlobatannins, Flavonoids, Saponins, Tanins. Terpenoids, Steroids, Glycosides, Anthroquinone, Quinine and Coumarin contents were assessed qualitatively in the leaf, bulb and root extract of P. pallida (Table 1 and 2). In the qualitative test of alkaloids (Table 1) Dragendroff's, Wagner's and Tannic acid reagents appeared more effective to which plant extracts exerted their moderate $(2+$ and $3+)$ response while, Hager's and Mayer's reagents seemed to be less effective to which they responded very mild (+) or negative (-).

Table1. Qualitative test for alkaloids of Pholidota pallida Lindl

\begin{tabular}{|c|c|c|c|c|c|}
\hline Plant parts used & \multicolumn{5}{|c|}{ Qualitative estimation of alkaloids by different reagents } \\
\hline & D & H & M & W & T \\
\hline Leaf & +++ & - & + & +++ & +++ \\
\hline Bulb & +++ & - & - & +++ & +++ \\
\hline Root & - & - & - & +++ & ++ \\
\hline
\end{tabular}

Notes: Name of the reagents, D-Dragendroff's reagent, H-Hager's reagent, M-Mayer's reagent, W-Wagner's reagent and Tannic acid reagent.

Table-2 illustrates that, Tanin is present but Phlobatannins, and Anthroquinone are absent in every part. Flavonoids, Saponins, and Steroids are present in leaf and bulb but absent in root. Terpinoids and Coumarins are present in leaf and root but absent in bulb. Quinine is absent in leaf but present in bulb and leaf. Glycoside is only present in bulbs. Nagananda et al. ${ }^{[26]}$ also screened Pholidota pallida Lindl from India and noticed alkaloids, flavonoid, phytosterols, and phenols in it.

Table2. Qualitative test for ten other secondary metabolites of Pholidota pallida Lindl

\begin{tabular}{|c|c|c|c|c|c|c|c|c|c|c|}
\hline \multirow{2}{*}{$\begin{array}{c}\text { Plant parts } \\
\text { used }\end{array}$} & \multicolumn{10}{|c|}{ Secondary metabolites (\% of coloration) } \\
\cline { 2 - 12 } & Phl. & Flv. & Sap. & Tan. & Ter. & Str. & Gly. & Anthr. & Qui. & Cou. \\
\hline Leaf & - & + & + & + & + & + & - & - & - & + \\
\hline Bulb & - & + & + & + & - & + & + & - & + & - \\
\hline Root & - & - & - & + & + & - & - & - & + & + \\
\hline
\end{tabular}

Notes: Phl= Phlobatannins, Flv= Flavonoids, Sap= Saponins, Tan= Tanins. Ter $=$ Terpenoids, Str $=$ Steroids, Gly= Glycosides, Anthr= Anthroquinone, Qui= Quinine, Cou= Coumarin.

Above outcomes indicate that, distribution of secondary metabolites is sporadic and uneven in various parts of the plant. Similar results were also observed by Rahman et al. ${ }^{[27]}$. Plants having metabolites seemed to exert antimicrobial, antioxidant, antifungal, anticancer and anti-inflammatory properties in several bioassays ${ }^{[28-29]}$. Thence, the plant was prompted to carry out further bioactive studies (antioxidant, Anti-inflammatory and antimicrobial tests) on it; ${ }^{[30]}$. Moreover, orchids are well known for having bioactivities and potential sources of antioxidants ${ }^{[31]}$. Different fractions at different concentrations $(50,100,150,200$ and $250 \mu \mathrm{g} / \mathrm{ml})$ also approved it (Fig 1-3) during their scavenging activity compared to ascorbic acid $(98.39 \%$ at $50 \mu \mathrm{g} / \mathrm{ml})$. BW fractions at low concentrations $(50 \mu \mathrm{g} / \mathrm{ml})$ showed strong scavenging activities which were $98.94 \%$ for bulb, $95.17 \%$ for root and $91.40 \%$ for leaf. FM parts were also found abuzz at the same dose for root $(95.02 \%)$ and bulb $(94.45 \%)$ but for leaf $(91.80 \%)$ it required higher dose $(200 \mu \mathrm{g} / \mathrm{ml})$. But, FD became vivid at higher concentration i.e. at $150 \mu \mathrm{g} / \mathrm{ml}$ for root $(96.22 \%)$ and leaf $(94.21 \%)$ and bulb $(95.66 \%)$ at $100 \mu \mathrm{g} / \mathrm{ml}$. On the other hand, FH disclosed their utility at maximum dose i.e. root $(95.90 \%$ at $200 \mu \mathrm{g} / \mathrm{ml})$, and leaf $(80.79 \%$ at $250 \mu \mathrm{g} / \mathrm{ml})$, except bulb $(90.19 \%)$ at $50 \mu \mathrm{g} / \mathrm{ml}$. According to Jun et al ${ }^{[32]}$, extract having scavenging activity below the range of $250 \mu \mathrm{g} / \mathrm{ml}$ dose is the indication of have significant antioxidant properties. From the above result it was inferred that, this plant has prominent antioxidant profile. Schinella et al ${ }^{[33]}$ reported that, antioxidant plants are also effective as anti-inflammatory 
being. So, to detect this finding, all fractions were screened for their anti-inflammatory entity (Fig 49). Among the fractions of plant parts, the responses of different fractions were also unique. In case of FD, strong ( $79.16 \%$ for leaf), and mild $(21.89 \%$ for root and $10.21 \%$ for bulb) anti-inflammatory effects were observed. But in FM, bulb (69.80\%) was found more effective than leaf $(40.63 \%)$ and root (14.30\%). In FH, leaf (44.80\%) was found effective than bulb (28.59\%) and root (15.63\%). Consequently, in BW parts, root $(43.75 \%)$ exerted more inhibitory effects than leaf $(22.92 \%)$ and bulb $(18.38 \%)$.

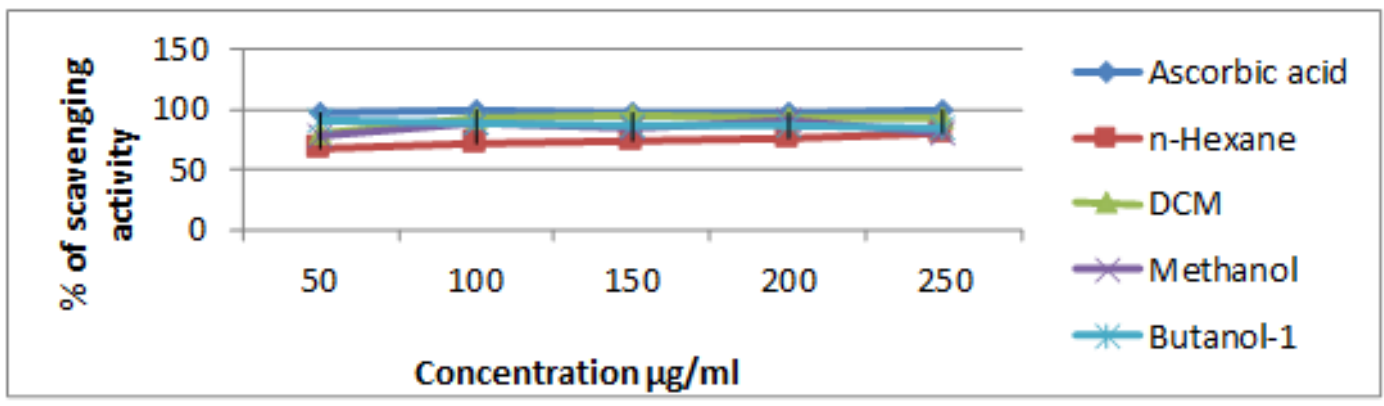

Fig1. Relative \% of Scavenging activity or \% inhibition of standard antioxidant Ascorbic acid and Methanol, $n$ Hexane, Butanol and DCM fraction of leaf of Pholidota pallida Lindl.

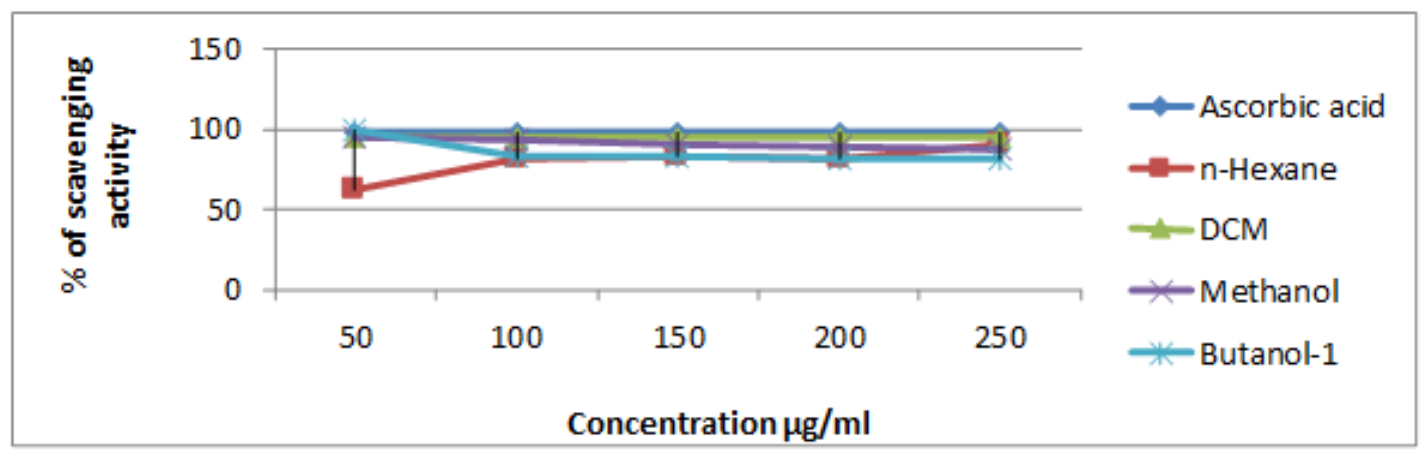

Fig2. Relative \% of Scavenging activity or \% inhibition of standard antioxidant Ascorbic acid and Methanol, $n$ Hexane, Butanol-Iand DCM fraction of bulb of Pholidota pallida Lindl.

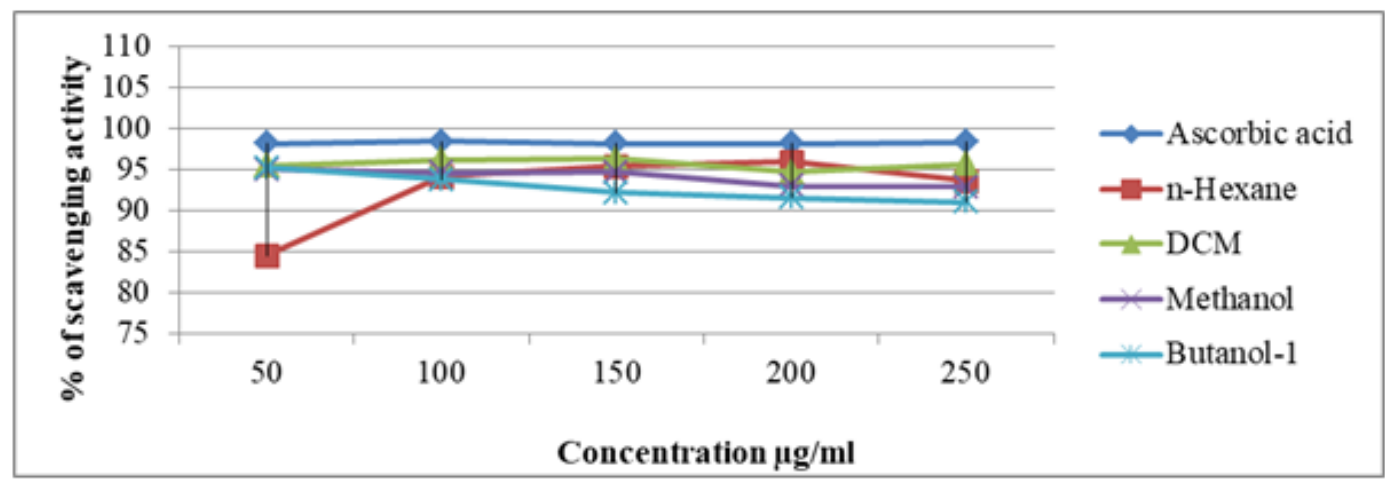

Fig3. Relative \% of Scavenging activity or \% inhibition of standard antioxidant Ascorbic acid and Methanol, $n$ Hexane, Butanol-1 and DCM fraction of root of Pholidota pallida Lindl.

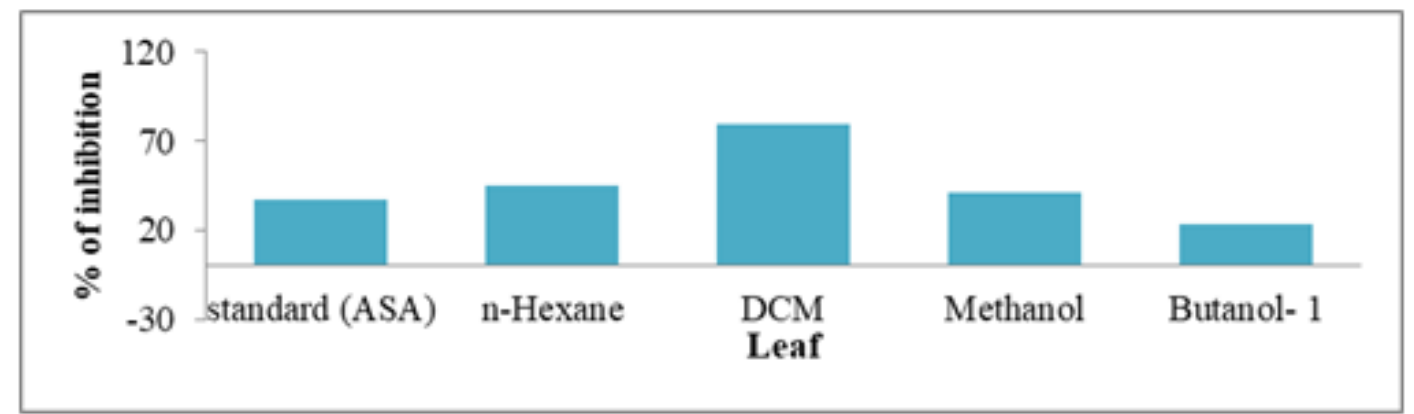

Fig4. Anti-inflammatory activity of different fractions of Pholidota pallida Lindl leaf 


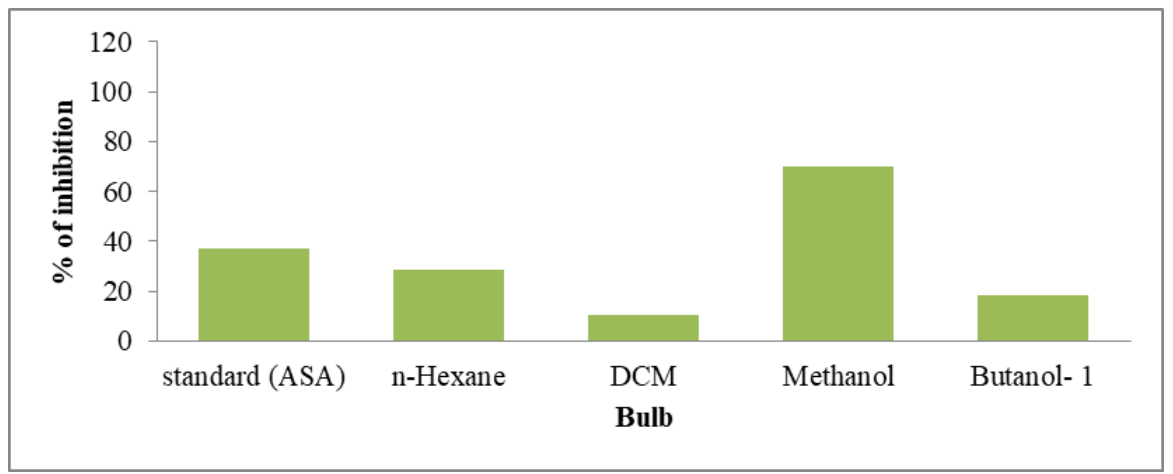

Fig5. Anti-inflammatory activity of different fractions of Pholidota pallida Lindl. bulb

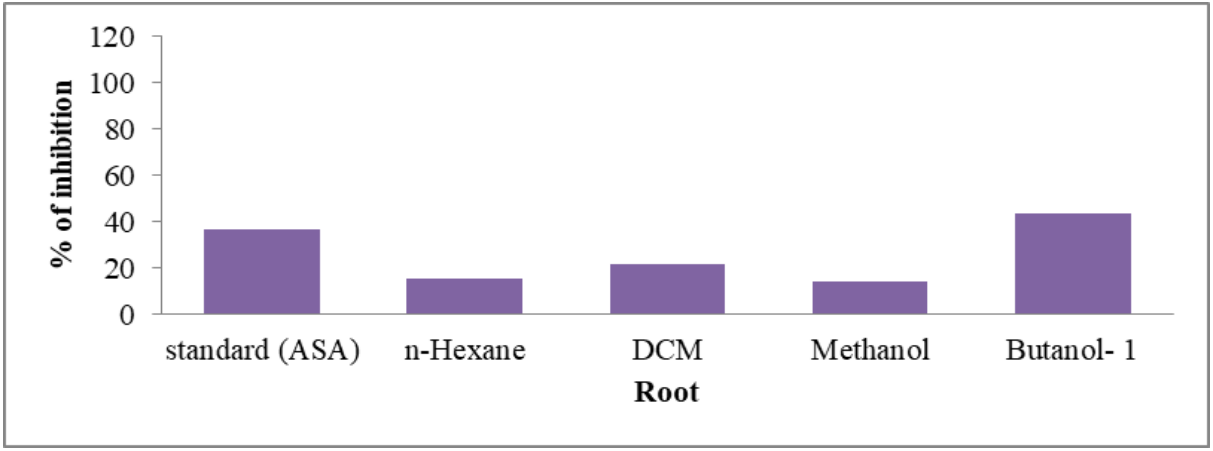

Fig6. Anti-inflammatory activity of different fractions of Pholidota pallida Lindl. root

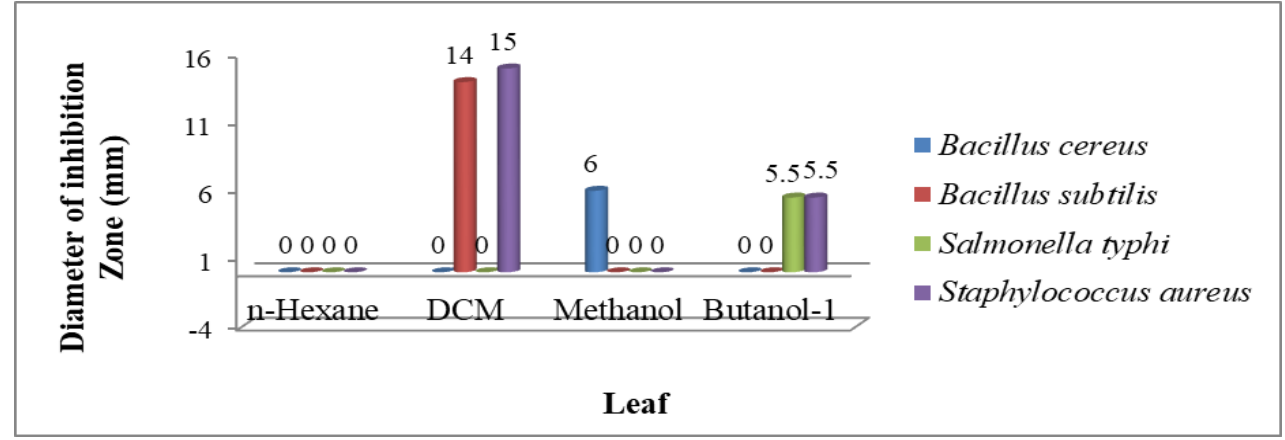

Fig7. Anti-bacterial activity of different fractions of Pholidota pallida Lindl. leaf

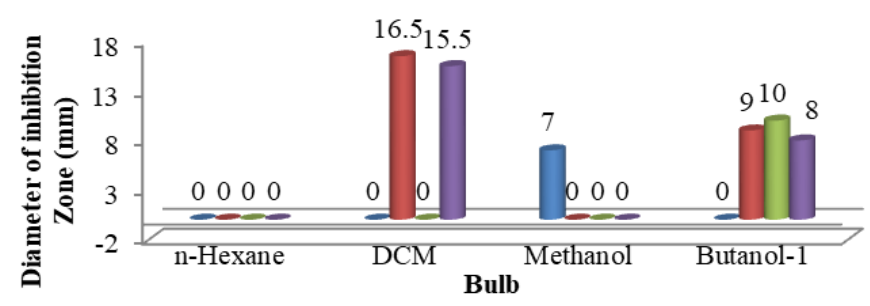

- Bacillus cereus

- Bacillus subtilis

- Salmonella typhi

- Staphylococcus cureus

Fig8. Anti-bacterial activity of different fractions of Pholidota pallida Lindl. bulb

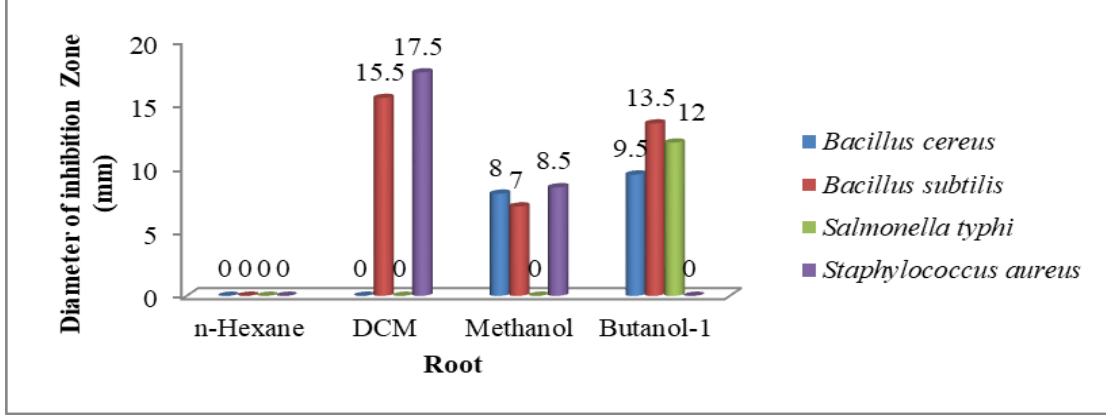

Fig9. Anti-bacterial activity of different fractions of Pholidota pallida Lindl. root 
Chinsamy et al. ${ }^{[34]}$ also observed incredible antioxidant and anti-inflammatory potency of orchids which were also harmonious to the present investigation while he was screening some indigenous orchids of South Africa. Such influential outcome amplified the plant to check its inhibition against bacteria as anti-inflammatory plants also possess antibacterial activity ${ }^{[35]}$. For investigating the antimicrobial potential, inhibitory effect of plant part fractions against four human pathogenic bacteria were cross examined compared to positive control (Ampicillin $25 \mu \mathrm{g} / \mathrm{disc}$ ). During this investigation it was noticed that, FH fractions of the plant is inert against the four pathogenic bacteria and only BW part can inhibit S. typhi. On the other hand, FD of leaf (14 and $15 \mathrm{~mm})$, stem $(16.5$ and $15.5 \mathrm{~mm})$ and root (15.5 and $17.5 \mathrm{~mm}$ ) is highly effective against $B$. subtilis and $S$. aureus but unresisting against $B$. cereus and $S$. typhi. FM of all parts inhibited B. cereus in the range of 6-8 $\mathrm{mm}$ but failed to avert $S$. typhi. In FM part only bulb had resistance against B. subtilis $(7 \mathrm{~mm})$ and $S$. aureus $(8.5 \mathrm{~mm})$. BW of all part the plant exhibited inhibitory effect against $S$. typhi of which root showed the maximum $(12 \mathrm{~mm})$. Sandrasagaran et al. ${ }^{[36]}$ experienced similar outcomes while working with an orchid (Dendrobium crumenatum) against 8 pathogenic bacteria. They found stem extract had the most potent antimicrobial activity against Staphylococcus aureus, Klebsiella pneumoniae and Entrobacter aerogenes while root and stem extracts were active against Streptococcus pneumonia, Shigella dysentriae and Saccharomyces cerevisiae.

\section{CONClusion}

The combined outcome implies that, extracts of different parts of this epiphytic orchid have ample phytochemicals with anti-oxidant, anti-inflammatory and antibacterial properties which can be a vital source of relevant drugs in the future.

\section{ACKNOWLEDGEMENT}

"We acknowledge Grants for Advanced Research in Education, Ministry of Education, GOB, for financial support and Department of Botany, University of Chittagong, Bangladesh for providing the lab facilities to conduct the current research."

\section{REFERENCES}

[1] Arora M., Mahajan A., Sembi J.K., A review on phytochemical and pharmacological potential of family Orchidaceae. Int. Res. J. Pharm. 8(10), 90-24 (2017).

[2] Maridass M., Hussain M.I., Raju G., Phytochemical survey of orchids in the Tirunelveli hills of South India. Ethnobotanical Leaflets. 12., 705-712 (2008).

[3] Puri H.S., American Orchid., Society Bulletin., 39:723. (1970)

[4] Kumar P., Panday A.K., Rawat G.S., Jalal J.S., Diversity and Conservation of orchids in state of Jharkhand. In: Plant Taxonomy: Advances and Relevance, CBS Publication, New Delhi, 345-353(2005).

[5] Behera. Ethnobotanical studies of some selected orchids and screening of their antimicrobial potential. M.Phil. thesis, North Orissa University., Orissa., India (2008).

[6] Ho and Chen. Moscatillin from the orchid Dendrobium loddigesii is a potential anticancer agent. Cancer Investigation 21, 729-736 (2003).

[7] Mazumder and Rahman. "Pharmacological Evaluation of Bangladeshi Medicinal plants for Antioxidant Activity. Pharmaceutical Biology, 46(10) 704-709 (2008).

[8] Rathee P., Chaudhury H., Rathee S., Rathee D., Kumar V., and Kohli K., Mechanism of action of flavonoids as anti-inflammatory agents; a review. Inflamm. Allergy Drug Targets., 8., 229-235 (2009).

[9] Huda M.K., Wilcock C.C., and Rahman M.A., The ethnobotanical information on indigenous orchids of Bangladesh. Hamdard Medicus. XLIX (3)., 138-144 (2006).

[10] Abraham and Vatsala., Introduction to Orchids., Tropical Botanic Garden and Research Institute., Trivandrum., 288-290(1981).

[11] Onaka AT., Komata S., Meada T., Kawazoe Y., Nutsuma M., Okamoto T. Chem Pharm Bull. 12: 50612 (1964).

[12] Deorani., S.C., and Naithani., H.B., Orchids of Nagaland, Oriental Enterprises, Deharadun. 1-364 (1995).

[13] Shrestha., R., Some medicinal orchids of Nepal. In: Watanabe., T., Takano., A., Bista., M.S. Saiju., H.K., Eds., The Himalayan plants., can they save us? In: Proceeding of Nepal-Japan joint symposium on conservation and utilization of Himalayan medicinal resources. Society for the Conservation and Development of Himalayan Medicinal Resources (SCDHMR)., pp. 153-156 (2000).

[14] Vaidya., B., Shrestha., M., Joshee., N., Report on Nepalese orchid species with medicinal properties. In: Proceeding of Nepal-Japan joint Symposium on conservation and utilization of Himalayan medicinal resources. Society for the Conservation and Development of Himalayan Medicinal Resources (SCDHMR)., Japan., pp. 146-152 (2000). 
[15] Baral S.R., Kurmi., P.P., A Compendium of Medicinal Plants of Nepal. Publisher Rachana Baral., Printed in Nepal by Mass Printing Press., Kathmandu (2006).

[16] Rajendra Yonzone., Ahsan Kamran and R. B. Bhujel., Orchids In Ethnobotany., International Seminar on "Multidisciplinary Approaches in Angiosperm Systematics" Kalyani. 661-669 (2008).

[17] Subedi A., New species, pollinator interactions and pharmaceutical potential of Himalayan orchids. Ph.D. Thesis., Leiden University., The Netherlands (2011).

[18] Yonzone R., Kamran., A., Bhujel., R.B., 2012. Orchids in Ethnobotany. In: Proceedings of International Seminar on Multidisciplinary Approaches in Angiosperm Systematics. University of Kalyani., Nadia. Vol. II., pp. 661-669 (2012).

[19] Sofowara A. Medicinal plants and Traditional medicine in Africa. Spectrum Books Ltd. Ibadan., Nigeria. 289(1993).

[20] Trease GE., Evans WC. Pharmacognosy. 11th edn. Brailliar Tiridel Can. Macmillian publishers. (1989).

[21] Harbrone JB. Phytochemical Methods. Chapman and Hall. Ltd. London.; 49-188 (1973).

[22] Bauer., A.W., Kirby W.M.M., Sheries J. C. and Turek M., Antibiotic susceptibility testing by a standardized single disc method. Am. J. Clin. Pathol. 45: 493-496 (1966).

[23] Brand-Williams W., Cuvelier M.E., Berset C., Use of a free radical method to evaluate antioxidant activity. Lebenson Wiss Technol. 28:25-30 (1995).

[24] Shinde U.A., Phadke A.S., Nair A.M., Membrane stabilizing activity: A possible mechanism of action for the anti-inflammatory activity of Cedrus deodara wood oil. Fitoterapia 70:251-7 (1999).

[25] Sangwan R.S., Chaurasiya N.D., Misra L.N., Lal P., Uniyal G.C., Sharma R., Sangwan N.S., Suri K.A., Oazi G.N., Tuli R., Phytochemical variability in commercial herbal products and preparations of withania somnifera (Ashwagandha) Current Science. 86:461-465. (2004).

[26] GS Nagananda., Patil A., Kambli J.V., S Rajath: Phytochemical Evaluation and invitro Free Radical Scavenging Activity of Cold and Hot Successive Pseudobulb Extracts of Medicinally Important Orchid Pholidota pallida Lindl. Adv. Biores. Vol 5(1): 100-105 (2014)

[27] Rahman M., Rahman A., Alamgir A.N.M., Phytochemical screening of some anticancer designate medicinal plants of Polypetalae. Journal of Pharmacognosy and Phytochemistry. 6(2): 177-180 (2017)

[28] Patwardhan B., Ethnopharmacology and drug discovery. J Ethnopharmacol.;100 (1-2):50-52. (2005).

[29] Rad J.S., Alfatemi S.M.H., Rad M.S. In vitro assessment of antibacterial activity of Salicornia herbacea L. seed extracts against multidrug resistant gram-positive and gram-negative bacteria. Int. J Biosci.;4(6):217222 (2014).

[30] Compean K.L., and Ynalvez R.A., Antimicrobial Activity of Plant Secondary Metabolites: A Review., Research journal of Medicinal plants. 8(5) 204-213 (2014).

[31] Stajner D., Popovic B.M., Canadanovic-Brunet J. and Goran A., Exploring Equisetum arvense L. Equisetum ramosissimum L. and Equisetum telmateia L. as source of natural antioxidants. Phyther Res. 23:546-550. (2009)

[32] Jun M., Fu HY., Hong J., Wan X., Yang CS., Comparison of Antioxidant Activities of Isoflavones from Kudzu Root (Pueraria lobata Ohwi). J Food Sci 68: 2117-2122 (2003).

[33] Schinella G.R., Tournier H.A., Prieto J.M., Mordujovichde Buschiazzo P., Ríos. J.L., Antioxidant activity of anti-inflammatory plant extracts; Life Sciences., 70( 9): 1023-1033(2002).

[34] Chinsamy. M., Finnie. J.F., Van Staden J., Anti-inflammatory., antioxidant., anti-cholinesterase activity and mutagenicity of South African medicinal orchids., South African Journal of Botany. 91: 88-98 (2014).

[35] Elvers K.T., Wright S.J., Antibacterial activity of the anti-inflammatory compound ibuprofen. Lett Appl Microbiol. 20(2): 82-4 (1995).

[36] Sandrasagaran U.M., New perspective of Dendrobium crumenatum orchid for antimicrobial activity against selected pathogenic bactria., pak.J. Bot., 46(2):719-724 (2014).

Citation: Seema Akter et al.. "Phytochemical Profiling and Bioactivities of Pholidota pallida Lindl" International Journal of Advanced Research in Botany (IJARB), vol. 5, no. 1, pp. 8-13, 2019. http://dx.doi.org /10.20431/2455-4316.0501002

Copyright: (C) 2019 Authors. This is an open-access article distributed under the terms of the Creative Commons Attribution License, which permits unrestricted use, distribution, and reproduction in any medium, provided the original author and source are credited 